\title{
Differenz
}

Revista internacional de estudios heideggerianos y sus derivas contemporáneas

AÑO 2 NÚMERO 1: JULIO DE 2015. e-ISSN: 2386-4877 - DOI: 10.12795/Differenz.2015.i01.02

[pp. 25-41]

Recibido: 03/06/2016

Aceptado: 20/06/2015

\section{El acontecimiento, la diferencia y lo sagrado en la filosofía de Heidegger.}

The event, diference and the sacred in Heidegger's philosophy

\author{
Juan Pablo E. Esperón \\ USAL (San Miguel), UNLAM, ANCBA, CONICET
}

\section{Resumen:}

En el presente artículo nos proponemos aportar algunos elementos desde el pensamiento heideggeriano para abordar la irrupción de la novedad sin remitirla o atribuirla a un fundamento organizador. Para ello, el desarrollo de las nociones de acontecimiento, diferencia y sacralidad nos han permitido repensar filosóficamente la novedad de un modo alternativo al de la tradición filosófica occidental.

Palabras Clave: Acontecimiento, diferencia, sagrado 


\section{Abstract:}

In this article we intend to provide some elements from Heidegger's thought to think the novelty. Therefore, we develop the notions of event, difference and sacredness. These notions help us to rethink the novelty of a different way to Western philosophical tradition. Keywords: Parrhesía, Intimacy, Freedom, Care.

\section{Introducción}

Heidegger ha hecho grandes esfuerzos para pensar la realidad fuera de los límites de las categorías tradicionales de la filosofía occidental. Debido a ello, este pensador es uno de los pioneros en postular la noción de acontecimiento y diferencia para abordar de otro modo los problemas ontológicos reunidos bajo la noción "ser" que se han planteado en la historia de la filosofía; y cuyos desarrollos cargan con un caudal tan grande de problemas, significaciones e interpretaciones que han terminado en muchos equívocos y malos entendidos; hasta llegados al punto de que, actualmente, con la voz "ser", no puede plantearse ningún problema ni decirse nada nuevo. En este sentido es que Heidegger inaugura un nuevo modo de hacer filosofía cuyo carácter distintivo es el de replantear los problemas ontológicos centrales de esta actividad, i. e.: "qué es la realidad", "por qué hay realidad pudiendo no haberla" y "cómo acceder a ella, i. e., cómo pensarla" postulando un otro movimiento del pensamiento que tiene como eje fundamental la noción acontecimiento y cuyo tratamiento se muestra en intima relación con las categorías de diferencia, tiempo y sacralidad.

Por ello resulta de suma relevancia para la filosofía actual preguntarnos qué es un acontecimiento y así poder aprehender que implicancias conlleva esta noción para la compresión de la novedad en una realidad que, en su carácter contingente, se nos presenta y nos afecta.

\section{Estado de la cuestión.}

El problema específico que aquí nos ocupa, entonces, se inserta en el marco general de las discusiones actuales y contemporáneas en torno al problema de la noción de diferencia, en particular la distinción heideggeriana entre la diferencia óntica y la diferencia ontológica. La filosofía como la literatura y las artes, a diferencia de las ciencias, no han dejado de plantearse desde hace tiempo el problema de lo nuevo, de la novedad, de la posibilidad de crear o de inventar una nueva forma de pensamiento que no sea 
una repetición más o menos sutil o una interpretación más o menos sugerente de lo ya producido por la filosofía en su historia anterior. Ya en 1806 Hegel había sostenido que la filosofía había llegado a su culminación y se había convertido en "saber absoluto", único al que cabe el nombre de ciencia verdadera. De allí en más, el marxismo, el positivismo, la filosofía analítica, el estructuralismo, entre otras influyentes corrientes de pensamiento, han proclamado el fin de la metafísica y la muerte de la filosofía, de lo cual se deriva la imposibilidad de pensar la novedad. Desde los años 30' en Alemania con el llamado giro o viraje (Kehre) que Heidegger produce en el planteo de los problemas de su filosofía; y en la segunda parte del siglo XX, en el ámbito francés, en particular, pensadores como Derrida, Foucault y Deleuze rechazaron decididamente estas alternativas impuestas por la coyuntura histórica y afirmaron la posibilidad de "pensar de otro modo". ¿Es posible pensar de otro modo? ¿De qué manera? ¿No se está en todos los casos dentro de las alternativas planteadas desde las formas de pensamiento hegemónicas? ¿Cómo dar lugar a la novedad si ya todo ha sido pensado?

\section{Planteo del problema: La insuficiencia de las categorías metafísicas para pensar la irrupción de la novedad en el pensamiento de M. Heidegger.}

Para Heidegger la filosofía es aquel pensar propio de occidente que busca determinar al ente en su ser. Su punto de partida está en los entes mismos, en lo finito, en lo limitado, en las cosas mismas. El ser-humano, en cuanto ser mortal, está entre medio de ellas y tropieza con ellas en las dimensiones propias de su existencia: el espacio y el tiempo, lo que implica la apertura del mundo como mundo. Así, la filosofía se constituye como tal, al configurar un modo propio de preguntar sobre los entes. Entonces, por un lado, la cuestión fundamental inherente a esta actividad es: ¿qué es el ser del ente?, esto es: preguntarse por el ente en cuanto tal, es decir, qué es en general lo que mienta al ente en cuanto ente. Esta pregunta apunta a la estructura ontológica de todo ente. Por otro lado, se cuestiona ¿por qué es el ente y no más bien la nada?, esta pregunta resalta el carácter contingente de todo ente mundano; pero, equívocamente, a lo largo de la historia occidental se ha asociado la respuesta a dicha pregunta, con el ente superior a partir del cual todo surge y del que todo depende. Esta interrogación apunta a la estructura teo-lógica del ente supremo. Por ello es que para Heidegger la filosofía y más específicamente, la metafísica occidental se ha constituido en íntima unión onto-teo-lógica. Es muy difícil explicar la procedencia de tal constitución, pero una de las hipótesis que podemos aventurar es la gran dimensionalidad que implica la noción "ser". 
Entonces, la metafísica es aquella disciplina que teoriza sobre el ente en cuanto ente, en busca de su estructura general -ontología-, y teoría del ente supremo del cual dependen todos los demás entes -teología. La doble configuración de la metafísica como onto-teo-logía presenta conexiones que no han sido problematizadas en sus raíces comunes. Cuestionarlas equivale a pensar lo in-pensado ${ }^{1}$ en la metafísica, esto implica, de algún modo, estar fuera de ella. Heidegger llama "historia de la metafísica" a la forma de pensar que desde Platón a Nietzsche se despliega como teoría general del ser del ente y como teoría del ente supremo (onto-teo-logía), dado que se ha olvidado al ser mismo y su diferencia con el ente, a favor del ser como fundamento del ente. Pero acá aparece un extravío o enlace equívoco porque se identifica al ser con aquel ente que fundamenta y causa toda existencia. ${ }^{2}$ Tal identificación es la que hace posible, a la vez, pensar al ser como fundamento. Pero al identificar al ser como fundamento de lo ente se olvida la diferencia en cuanto tal, esto es, la diferencia entre ser y ente. ${ }^{3}$ Aceptado esto, se abre el camino para que el ente supremo, y a través de la concatenación entre causas y efectos, se constituya en fundamento $y$, a la vez, en causa primera de todo lo existente. Ello constituye el olvido de la diferencia y la imposibilidad de pensar la irrupción de la novedad en cuanto tal, pues lo nuevo siempre es explicado y atribuido a un ente superior, o fundamentado por un ente supremo que funciona como centro organizador, garante de la existencia de todo ente y dador de sentido, conforme al modo de pensar onto-teo-lógico explicitado aquí.

Entonces, lo decisivo dentro de este aspecto, y que Heidegger ha señalado lúcidamente, es que la metafísica se desarrolla como actividad que supone al pensamiento dentro del horizonte onto-teo-lógico, pero no convierte a la dimensión del ser mismo y a la relación que este tiene con lo ente en problema; es decir, no se pregunta qué es la diferencia y por qué hay acontecimiento. Solo se problematiza y se desarrolla la cuestión de lo ente. En Platón, por ejemplo, lo ente aparece como aspecto o idea cuya estabilidad y unidad hacen que permanezca idéntica a sí misma. Por el contrario, las cosas sensibles muestran

1 Lo no-pensado no se refiere a todo aquello que la filosofía dejó de pensar, o los temas que quedaron marginados de la reflexión y del pensar conceptual, sino más bien a lo que aparece como olvidado en la historia de la metafísica, pero que, precisamente, por aparecer así, ha dado lugar a la misma metafísica. Lo in-pensado no fue olvidado al principio de esa historia, y por eso no es algo que hubiera que recuperar, sino que es lo que está presente en cada pensador en el modo de la ausencia.

2 Tal identificación es posible porque está supuesta y opera la lógica de la identidad que Heidegger muestra claramente en su conferencia sobre "El principio de Identidad", en Identidad y Diferencia, Trad. H. Cortés y A. Leyte, Anthropos, Barcelona, 1990.

3 Cfr. ESPERón, J. P., "Metafísica y post-filosofía en el pensamiento de Martin Heidegger”, en RIHUMSO. Revista de Investigación en Humanidades y Ciencias Sociales dependiente del Departamento de Humanidades y Ciencias Sociales de la Universidad Nacional de La Matanza, San Justo, Bs. As. Año II, número 4, 2013, p. 35. 
una inestabilidad en tanto devienen, surgen y desaparecen; en tanto entes sensibles su ser consiste en participar o imitar a las ideas. En Aristóteles ello tiene el carácter de interpretación categorial de la ousía, como también la comprensión de la cosa como obra (ergon) ${ }^{4}$ en el ámbito de la dýnamis ${ }^{5}$ y la energeia. ${ }^{6}$ Ahora bien, este esquema o estructura que define a la metafísica onto-teo-lógicamente no puede ser atribuido absolutamente ni a Platón ni a Aristóteles; aunque Heidegger sostenga, que en Aristóteles, la metafísica se constituyó como tal. ${ }^{7}$ Numerosos estudios han demostrado que ello es insostenible. Sin embargo, podemos afirmar que el discurso metafísico que aquí está en cuestión para Heidegger, se ha afianzado, de tal modo, conforme a la tradición medieval, a la asimilación y apropiación de la filosofía griega por el mundo cristiano; y, fundamentalmente, a las discusiones escolásticas y a la relectura de Aristóteles en clave teológica.

Ahora bien, ¿es posible pensar la irrupción de la novedad en cuanto tal?, ¿qué es un acontecimiento?, ¿por qué el acontecimiento implica pensarlo en el horizonte del tiempo y la diferencia?, ¿’por qué el acontecimiento supone, también, pensar de un nuevo modo lo sagrado? El desarrollo del texto que sigue tiende a problematizar esta cuestión determinante para situarnos y habitar un mundo cuyo carácter resulta absolutamente contingente.

\section{Heidegger, una filosofía del acontecimiento, la diferencia y lo sagrado.}

"Ser' significa que el ente es
y no no-es. 'Ser' nombra este
'que' como la decisión con que
acontece el alzarse contra la
nada".

\section{II.A. La diferencia.}

Los problemas en torno a la diferencia, el acontecimiento y el tiempo se desarrollan a lo largo de toda la obra de Heidegger. Allí estas nociones son puestas en primer plano y problematizadas. En Ser y Tiempo, quizás su gran obra, Heidegger elabora un plan de delimitación de la ontología metafísica. Parte de una insuficiencia sobre la noción de ser,

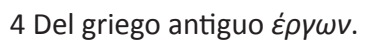

5 Del griego antiguo $\delta u ́ v \alpha \mu \iota$.

6 Del griego antiguo $\varepsilon v \varepsilon ́ \rho \gamma \varepsilon\llcorner\alpha$.

7 Cfr. HEIDEGGER, Martin, Conceptos fundamentales, Alianza, Madrid, 1990.

8 HEIDEGGER, Martin; Nietzsche II, Destino, Madrid, 2000, p. 327.
} 
transmitida por tal historia de la metafísica, para comprender "lo que es" y al hombre mismo. Pero a su vez, es él mismo el que se pregunta por el sentido del ser y cuestiona la noción de ser transmitida por la metafísica. Como es sabido, también, Sein und Zeit se encamina a señalar al tiempo como horizonte de la pregunta por el sentido del ser como acontecimiento apropiante (Ereignis), llegando a la indicación de que el ser se da dentro del horizonte del tiempo, en el sentido que es el instituirse mismo de la temporalidad como unidad de los tres éxtasis: pasado, presente y futuro. Esta problemática del ser, de la que no puede darse una definición, es la base de la diferencia y, a su vez, este problema ya es el de Ser y Tiempo, porque al plantearse el interrogante por el sentido del ser se evidencia su diferencia con los entes. Pero la teorización de la diferencia como resultado del planteo de Ser y Tiempo, se encuentran en un ensayo posterior, de 1929, Ilamado "La esencia del fundamento" donde Heidegger afirma:

"El no ser escondido del ser significa siempre la verdad del ser del ente, sea este real o no. Recíprocamente, en el no ser escondido de un ente está siempre implícita la verdad de su ser. La verdad óntica y la verdad ontológica se refieren, respectivamente, al ente en su ser y al ser del ente. Ellas se compenetran esencialmente en base a su relación con la diferencia (Unterscheid) entre el ser y el ente (ontologische Differenz). La esencia de la verdad - que por eso se bifurca necesariamente en óntica y ontológica-, sólo es posible, junto al abrirse de esta diferencia". ${ }^{9}$

Aquí la diferencia se da entre lo que aparece en un cierto horizonte temporal y el horizonte mismo como apertura que posibilita la aparición del ente. Ahora bien, Heidegger muestra que en la exegesis historiográfica la pregunta por la diferencia (ontológica) resulta extraviada u olvidada pues se ha reducido todo ente intramundano a la objetividad de la presencia, ello es, al concepto; posibilitando su control y manipulación. Pero en el fondo de esta cuestión emerge el problema radical de la filosofía, la pregunta por el carácter eminentemente contingente de la realidad: ¿por qué hay diferencia? Ello nos lleva a plantear el problema de la diferencia fuera de los límites de las estructuras categóricas de la metafísica.

La diferencia, desde este otro modo de pensar, implica pensarla ubicándonos en otra dimensión que el lugar otorgado a la diferencia onto-teo-lógica en la historia de la metafísica. Pensar aquella (Unterscheidung) ${ }^{10}$ significa que hay que comprender al ser del

9 HEIDEGGER, Martin, “La esencia del fundamento", en Hitos, Alianza, Madrid, 2000, p. 126.

10 Inter-cisión. Es la es-cisión entre (del latín inter) ser y ente, que resulta inter porque a su vez están referidos el uno al otro. "La diferencia de ser y ente, en tanto que inter-cisión entre la sobrevenida y la llegada, es la resolución desencubridora y encubridora de ambas. En la resolución (Austrag) 
ente como genitivo ${ }^{11}$ objetivo ${ }^{12}$ y genitivo subjetivo ${ }^{13}$ a la vez. Aquí está implícita siempre la diferencia en cuanto tal. Ambos, ser y ente, están vinculados, mutuamente se pertenecen. En el primer caso se indica que el ser pertenece a lo ente y, en el segundo caso, se indica que lo ente pertenece al ser mismo. Así, se convierte en asunto del pensar a la diferencia en cuanto tal, es decir, en cuanto "diferenciante". El participio presente indica la donación del ser respecto a lo ente. Es fundamental comprender al "es", en el lenguaje, como un tránsito a... El ser sobreviene en el ente y lo desoculta, pero a su vez, el ser se oculta en aquello que desoculta. Esta trascendencia del ser, como sobrepasamiento y donación en lo ente al que llega, ad-viene. Este es el sentido propio del participio presente; es una tensión que se "da" entre (Zwischen) ambos y se mantiene. Así, Heidegger puede afirmar que "sobrevenida y llegada están a la vez separadas unas de otra y referida la una a la otra". ${ }^{14}$

\section{II.B. El acontecimiento.}

Pero a su vez, para Heidegger la noción de diferencia está íntimamente ligada a la noción de mismidad enunciada por Parménides: "ser y pensar son lo mismo". Pero, para Heidegger, la mismidad de pensar y ser, que se halla en la frase de Parménides, procede desde otra dimensión, distinta al lugar de la identidad determinada por la metafísica donde se identifica al ser con el ente supremo. La mismidad de pensar y ser es mutua pertenencia (Zusammengehören) ${ }^{15}$ entre (Zwischen) ambos. Esta identidad originaria que sale fuera de la representación de la metafísica, habla de una "mismidad" a partir de la cual tiene su lugar el pensar y el ser; desde lo cual ser y pensar se pertenecen mutuamente. ¿Qué es esta mismidad? La mutua pertenencia entre ser y pensar. ${ }^{16}$ Pero ¿ser y pensar no son dispares? El hombre no es simplemente un ser racional -con esta determinación la

reina el claro (Lichtung) de lo que se cierra velándose y da lugar a la separación y la reunión de la sobrevenida y la llegada". HEIDEGGER, Martin, Identität und Differenz, Gesamtausgabe 11, Vittorio Klostermann, Frankfurt an Main, 2006. Nosotros utilizamos y citamos a lo largo del texto la edición bilingüe de Identidad y Diferencia, Trad. H. Cortés y A. Leyte, Anthropos, Barcelona, 1990. p. 141. En adelante para citar el texto en cuestión utilizaremos solamente la sigla "ID".

11 El genitivo indica posesión o pertenencia.

$12 \mathrm{El}$ ser es en tránsito a..., recae sobre lo ente.

13 Se acentúa el ser mismo en su sobre-llegar a lo ente

14 ID, p. 141.

15 Heidegger sostiene que el pertenecer (ge-horen) determina lo mutuo (zusammen), y no viceversa. Cfr. ID, 68-73.

16 Cfr. ID, p. 68-73. 
metafísica lo convirtió en un ente. El ser-humano ${ }^{17}$ es, en cuanto tal, pertenencia al ser, que resulta mutua porque el ser pertenece, asimismo, al hombre, ya que solo así "es", acontece. No hay preeminencia de uno sobre el otro; hay una vinculación respetando cada uno su lugar en su mutua pertenencia; pero a su vez, en su diferencia originaria. ${ }^{18} \mathrm{De}$ este modo, según la comprensión heideggeriana desde el pensar fundante o desde otro modo de pensar, la frase de Parménides dice "el ser tiene su lugar - con el pensar - en lo mismo" (Sein gehört - mit dem Denken- in das Selbe)". ${ }^{19}$ Y ¿qué es ese "lo mismo" para el pensar no metafísico de Heidegger? Lo que da (es gibt) tanto al ser como al pensar su mismidad, es su mutua pertenencia. Entonces, ese mutuo pertenecerse acontece, para Heidegger, como acontecimiento apropiante (Er-eignis). ${ }^{20}$ En el Er-eignis hombre y ser se pertenecen.

Heidegger propone, para llevar a cabo este otro modo de pensar, dos movimientos complementarios. Por un lado, el pensar debe moverse dando un "paso atrás" (der Schritt zurück), preguntando y haciendo asunto de litigio a la diferencia en cuanto tal, observando que la diferencia onto-teo-lógica no es la diferencia originaria que los primeros pensadores (presocráticos) señalaron. Pues, al hacerse patente lo no pensado, la diferencia ontológica, el pensar puede volver a preguntarse por la diferencia. Por otro lado, el pensar debe moverse dando un "salto" (der Absprung), más allá o por fuera de la metafísica, para pensar el vínculo que se manifiesta en la relación entre el ser y el hombre. Este salto, es un salto más allá de la historia acontecida, es un movimiento del pensamiento en dirección al ser mismo y su sentido, que acontece como mutua pertenencia de ser y pensar. Pero el salto, también, nos trae de regreso a la época actual donde el dominio técnico se ha universalizado. De este modo, Heidegger afirma que:

\footnotetext{
"la mutua pertenencia de hombre y ser a modo de provocación alternante, nos muestra sorprendentemente cerca, que de la misma manera que el hombre es dado en propiedad al ser, el ser, por su parte, ha sido atribuido en propiedad al hombre. En la com-posición reina un extraño modo de dar o atribuir propiedad. De lo que se trata es de experimentar sencillamente
}

17 En la noción ser-humano se devela la relación presente entre (zwischen) ser y hombre. Del mismo modo que se señala la íntima relación entre la identidad y la diferencia. La identidad, mismidad entre ser y hombre, es en la diferencia-diferenciante (Unterscheidung).

18 Cfr. ID, p. 68-73.

19 ID, p. 69.

20 ID, p. 91. 
este juego de apropiación en el que el hombre y el ser se transpropian recíprocamente, esto es, adentrarnos en aquello que nombramos Ereignis". ${ }^{21}$

La con-posición (Ge-Stell) ${ }^{22}$ nos lleva al Ereignis que podemos traducir como acontecimiento apropiante, pero Heidegger afirma que esta palabra, como palabra conductora de su pensamiento, no se deja traducir al igual que el lógos griego. Ella remite, etimológicamente, a Er-auguen, que significa asir con la mirada, apropiar. En la con-posición ser y hombre están referidos el uno al otro, el uno se apropia del otro; pero si penetramos, con la mirada en lo profundo de la con-posición, experimentamos el Ereignis, en donde ser y hombre están en relación de mutua pertenencia y, de este modo, acontecen. Pero Heidegger dice:

“...lo que experimentamos en la composición como constelación de ser y hombre, a través del moderno mundo técnico, es solo el preludio de lo que se llama acontecimiento de transpropiación (Ereignis). Pero la com-posición no se queda necesariamente detenida en su preludio, pues en el acontecimiento de transpropiación habla la posibilidad de sobreponerse al mero dominio de la com-posición para llegar a un acontecer más originario". ${ }^{23}$

Esto es el llevar adelante la posibilidad de trascender la Ge-Stell en dirección al Ereignis, el sobreponerse a la con-posición transformando, radicalmente, la relación del hombre con la técnica, ya no como dominio de lo ente en general, sino como al servicio del hombre y lo ente. Luego afirma Heidegger:

\section{ID, p. 85.}

22 Para Heidegger, la disposición en la que el hombre se relaciona con el ser sometiéndolo al cálculo pero que, al mismo tiempo, el hombre mismo es tomado como cosa, a quien le viene impuesto lo técnico, constituye nuestra constelación (Cfr, ID, p. 81). En esta constelación ser y hombres están relacionados como cosas, es decir, se toma al hombre como ente y al ser como ente, de este modo, ambos casos se identifican como objetos manipulables, disponibles y calculables. El hombre, mentor de la técnica omniabarcante, es desafiado por el ser de ésta, es decir, el hombre mismo se convierte en objeto de la tecno-ciencia. La constelación regida por la técnica, cuya consecuencia se despliega como consumación de la metafísica y sus posibilidades es lo que Heidegger nombra con la palabra Ge-Stell, noción de muy difícil traducción a la lengua hispana. En el alemán ordinario significa "armazón", pero que aquí traducimos por "con-posición". El Ge indica, en alemán, un conjunto, un colectivo, el guión indica que fijemos la atención en el verbo alemán Stellen ('poner, colocar'). Si ponemos la atención en la con-posición de nuestra época técnica, comprendemos esta constelación como lo calculable y asegurable, que a su vez, es mutua provocación alternante entre el ser y el hombre (Cfr, ID, p. 83). En esta mutua provocación, el ser aparece como algo disponible y almacenable; y el hombre como medio para un fin: material de trabajo, objeto de ciencia, de propaganda o de destrucción. El hombre es, desde esta perspectiva, mercancía, capital disponible. 23 ID, p. 87. 
“...el Ereignis es el ámbito en sí mismo oscilante, mediante el cual el hombre

y el ser se alcanzan el uno al otro en su esencia y adquieren lo que les es esencial al perder las determinaciones que les prestó la metafísica". ${ }^{24}$

Así, mediante el salto, abandonamos el lugar de la representación propia del pensar metafísico; y es posible, de este modo, la manifestación de una dimensión diferente, propio de un pensar contemplativo, donde ser y hombre mutuamente se pertenecen, se experimenta de un modo originario lo ente, y a la vez, se expropian las determinaciones metafísicas de la representación (sujeto-certeza-objeto). Este es un ámbito donde la llamada del ser se deja escuchar, y donde el hombre reconoce su pertenencia al ser, que a su vez, es mutua. Plantear la pregunta por la diferencia ontológica nos condujo, entonces, a este dejar pertenecer mutuo que se manifiesta en el Ereignis. De este modo, el movimiento de retroceso (paso atrás) y avance (salto) respecto de la metafísica, sitúan, su historia, en cuanto despliegue tecno-científico, como una época consumada; lo que significa, por un lado, no que ésta haya acabado o finalizado, sino que ella misma ha desplegado todas sus posibilidades de dominio; y, por otro lado, al desplegar todas sus posibilidades de dominio, la metafísica muestra sus propios límites, lo cual nos coloca, de algún modo, fuera de ella.

El "paso atrás" y el "salto" pueden ponerse en marcha, según Heidegger, si nos situamos en una dimensión diferente a la del modo de pensar de la metafísica. ${ }^{25} \mathrm{El}$ primer movimiento del pensamiento (el paso atrás) retrocede hacia el pasado, para develar los sentidos ocultos en los conceptos metafísicos. Este es un movimiento destructivo, pero de carácter positivo dado que se destruyen los sentidos equívocos que se habían acumulado sobre las nociones filosóficas fundantes. Esta destrucción es, al mismo tiempo, liberadora, porque permite a estas nociones mostrar su sentido originario. Este movimiento destructivo no pretende aniquilar el pasado, sino conservarlo como pasado. El segundo movimiento del pensamiento (el salto) regresa al presente para develar el aparato conceptual ilegítimo que impide pensar la diferencia y al acontecimiento en cuanto tales. En este movimiento, el pensar hace de la diferencia y el acontecimiento su asunto propio. Dado que es un salto hacia la ausencia de fundamento ( $A b$-grund), no por ello implica considerar, que el salto, es un brinco hacia el vacío, sino, por el contrario, es un salto hacia un nuevo suelo (Boden) como aquello que se retrae y sustrae en el darse (Es-gibt). Este movimiento es el que en cuanto rememoración (An-denken), recuerda y problematiza a la diferencia y al acontecimiento, cuestionando y haciendo asunto de otro modo de pensar

24 ID, p. 89.

25 Cfr. Introducción de Arturo Leyte a Identidad y Diferencia, Anthropos, Barcelona, 1990, p. 42. 
por qué hay diferencia y acontecimiento. Al contario del pensar fundamentador, propio de la metafísica, que sólo se concentra en la representación del ente en su ser, como ser presente, sin pensar su proveniencia. Pensar como "rememorar" significa captar la apertura del ser, captar el Ereignis. Este modo de pensar se dirige al ser como diferencia, no sólo como aquello que difiere, sino también como aquello que se da en el darse, pero que en ese mismo darse se sustrae; y también como aquello que, en su apertura, al diferir, disloca. Pensar, desde esta posición, significa preparar un pensar desde una dimensión desfundamentadora o, mejor dicho, desde una dimensión fundante.

\section{II.C. Lo sagrado}

En suma, Heidegger, vislumbra junto al comienzo tradicional de la filosofía como metafísica, cuya esencia gira en torno a la búsqueda de un fundamento (arkhé) absoluto que sea soporte de todo lo ente, a partir del pathos de la admiración que produce lo real; otro comienzo del pensar cuyo sentimiento fundamental es el temor (Scheu), la serenidad (Gelasenheit) y el espanto (Schrecken). ${ }^{26}$ Otro comienzo, no uno nuevo, porque se ubica en otra parte y no después, en otro estrato en el que el tiempo histórico se ilumina a partir de la concepción del ser como acontecimiento apropiante (Ereignis). ${ }^{27}$ Este es un lugar en el que ya todos habitamos, pero del cual siempre alejamos la mirada. Este otro comienzo es el paso de la consideración de la metafísica como onto-teo-logía, a la del ser y la diferencia como acontecimiento apropiante (Ereignis); y el paso del pensamiento que interroga por el fundamento de lo real asegurándolo en la objetividad de la representación, al pensamiento que está a la escucha del ser.

En Aportes a la filosofía, ${ }^{28}$ Heidegger habla de un primer comienzo que designa a toda la historia de la metafísica, y que, en su acontecer, se caracteriza por el olvido de la pregunta que interroga por el sentido del ser; pero también, muestra la posibilidad de otro comienzo que subyace en la elaboración de la pregunta ¿qué es el ser? y ¿por qué la diferencia? Este tránsito cobra sentido cuando Heidegger comprende la diferencia ontológica como Ereignis. Este es un tránsito de la verdad del ente hacia la verdad del

26 Cfr. HeIDEgGeR, Martin, Aportes a la Filosofía. Acerca del Evento, p. 20-23.

27 Desde el pensar fundante o desde otro modo de pensar Heidegger sostiene, "el ser tiene su lugar - con el pensar - en lo mismo" (Sein gehört - mit dem Denken-in das Selbe)" (ID, p. 69). Y ¿qué es ese "lo mismo" para el pensar no metafísico de Heidegger? Lo que da (es gibt) tanto al ser como al pensar su mismidad, es su mutua pertenencia. Ahora, ese mutuo pertenecerse acontece, para Heidegger, como Er-eignis (ID, p. 91). En el Er-eignis hombre y ser se pertenecen y se apropian mutuamente.

28 HEIDEgGer, Martin, Aportes a la Filosofía. Acerca del Evento, p. 36-38. 
ser, y a la problamatización de la diferencia. Heidegger encuentra el sentido pleno de este movimiento, en la consideración de la diferencia ontológica, como la relación entre Austrag y Lictung ${ }^{29}$ que adviene en cuanto Ereignis. Ello implica, según Heidegger, un tránsito del pensamiento donde se deja de comprender al hombre como amo y señor que lo domina todo a través de la tecno-ciencia, hacia la comprensión del ser como destinación (Geschick), y como donación del ser en forma de desocultamiento y ocultamiento a la vez. El tránsito es un camino o travesía hacia lo abismal o el abismo del ser, es decir, un recorrido desde el modo de pensar de la metafísica que todo lo fundamenta a la desfundamentación, o mejor dicho, a la fundación. El tránsito llega a realizarse a través del ensamble (Aufriss) que explica Heidegger en Aportes a la filosofía de la siguiente manera. En la resonancia se experimenta el abandono del ser, ello conduce al pase del primer comienzo al otro, a través de un salto hacia lo abismal del ser, y en torno a su verdad, en la cual comparecen los futuros con el fin de que pueda advenir el último dios. El tránsito se da aquí, estrictamente hablando, en el pase. El pase es la transición del primer comienzo al otro comienzo del pensar. ${ }^{30}$ Esto no significa desechar la historia de la metafísica sino, que desde el otro comienzo, dialogar con ella. ${ }^{31}$

¿Qué significa historia de la metafísica? Significa que la filosofía, que en su inicio pregunta ¿qué es el ser? desde su diferencia ontológica con lo ente, ha olvidado la diferencia-diferenciante, ha confundido esta diferencia con otra diferenciación: la diferencia onto-teo-lógica, diferencia que se da entre un ente supremo y todos los demás entes y que, a su vez, se constituye como fundamento de todo lo ente en general. Según Heidegger, esta diferencia, no originaria de la esencia de la filosofía, se convierte en el motor que pone en marcha a la metafísica en cuanto dominación y en cuanto manipulación de todo lo ente en general, hasta su consumación en la época moderna.

Pero, dado que a través de la tradición metafísica recibimos lo pensado; pero que implica, también, lo in-pensado en ella, esto, a su vez, posibilita tanto el despliegue de la historia metafísica como su superación. Lo in-pensado se presenta como retracción (Entzug) y como velamiento (Lethe) pero nos atraviesa dejando su rastro o huella (Spur). A partir de atender a estas huellas es posible el pensamiento rememorante, es decir, pensar

\section{Ver nota número 10.}

30 Cfr. ESPERón, J. P., "Metafísica y religión. Caminos hacia un replanteamiento de la cuestión de lo divino a partir de las filosofías de Heidegger y Nietzsche", en HORIZONTES FILOSÓFICOS. Revista de Filosofía, Humanidades y Ciencias Sociales, Editada por las áreas "Epistemología" y "Problemáticas especiales de la filosofía: el lenguaje", Departamento de Filosofía, Facultad de Humanidades, Universidad Nacional del Comahue, Neuquén, Argentina. Año 2, número 2, 2012, p. 114.

31 Cfr. SANTIESteban, Luis Cesar, "Heidegger y Vattimo: intérpretes de Nietzsche", en Diánoia, volumen LIV, número 63, revista de la UNAM, México, 2009, p. 22-23. 
lo in-pensado (An-denken). Pues, lo que se sustrae puede tocar, o, mejor dicho, toca al hombre de modo tan grave que lo interpela más que la presencia de lo ente; entonces la filosofía debe meditar sobre aquellos signos de lo que se sustrae, preparar el pensar rememorante para el paso del último dios. Este último dios señala lo totalmente otro ante los dioses de la metafísica, ajeno a toda religión, fuera de lo calculable y extraño a las determinaciones del dios de la metafísica como ente supremo, creador, causa primera, etc., pero tampoco debe confundirse con el ser o el Ereignis del otro comienzo. Entonces, para acoger la venida del último dios es necesario prepara un claro (Lichtung), un lugar donde espacio y tiempo resultan sagrados como ámbito para el encuentro con lo divino. Desde el ser no se llega a lo divino, aunque la pregunta por el ser sea una instancia necesaria para su advenimiento. Heidegger señala que hay que preparar el lugar sagrado que nos abre la esencia de la divinidad, y así llegar a pensar la esencia de dios como lo divino.

Pero, ¿por qué ultimo dios? La noción heideggeriana último dios ${ }^{32}$ (der letzte Gott) refiere, por un lado, al eco del hombre frenético, que en la filosofía de Nietzsche, con dolor y en búsqueda de la divinidad, anuncia la muerte del dios de la metafísica; ${ }^{33}$ y por otro lado, último no refiere al final de una época sino al comienzo de otro modo de pensar, en donde a partir del Ereignis preparamos el espacio-tiempo sagrados para el instante de su paso. "El último dios es el comienzo de la más larga historia en su más corta vía. Se requiere larga preparación para el gran instante de su paso." ${ }^{34}$ El último dios no muestra el fin de la historia, como podría interpretarse, por el contrario, ello mienta la apertura inconmensurable y las infinitas posibilidades de un nuevo comienzo para la historia del hombre y su vínculo con lo divino. ${ }^{35}$

De este modo, Heidegger se esfuerza, también, por plantear el problema de la relación del hombre con lo divino en un nivel más radical que el de la metafísica. ${ }^{36}$ Por ello afirma que "el último dios (...) se halla fuera de toda determinación calculadora significada por

32 Aclaremos que la noción de Dios no debe confundirse con el tratamiento teo-lógico que está en cuestión en el texto, porque la teología no habla, en realidad de Dios como la divinidad, sino que mienta, en su concepto, el fundamento que unifica la totalidad de lo ente.

33 Cfr., NIETZSCHE, Friedrich W., La ciencia Jovial, Monte Avila, Caracas, 1990, p. 116-118.

34 HeIDEgGer, Martin, Aportes a la Filosofía. Acerca del Evento, op. cit., p. 332.

35 Cfr. CAPELle-DUMONT, Philippe, Filosofía y teología en el pensamiento de Martin Heidegger, FCE, México, 2012, p. 142-143.

36 John D. Caputo ya ha dado cuenta del interés, la vinculación y la influencia del pensamiento religioso en el pensamiento heideggeriano; fundamentalmente en lo que respecta a su vertiente mística en su libro The mistical elements in Heidegger 's thought, Ohio University Press, 1978. 
los títulos mono-teísmo, pan-teísmo y a-teísmo"; 37 pues partiendo de los entes y sus explicaciones causales al modo de la tecno-ciencia moderna no es posible la preparación de un lugar sagrado donde acoger el advenimiento de lo divino. Por ello sostiene Heidegger "Solo a partir de la verdad del ser se ha de pensar qué sea lo sagrado. Solo a partir de qué sea lo sagrado se ha de pensar qué sea la divinidad. Solo a la luz de qué sea la divinidad se puede pensar y decir qué deba nombrar con la palabra Dios". ${ }^{38}$

Resulta claro, entonces, que el ser heidegggeriano no debe confundirse con lo divino. A partir de la verdad del ser y el Ereignis, es decir desde el otro comienzo del pensar, es posible pensar la esencia de lo sagrado, dado que el Ereignis opera, en el pensamiento de Heidegger, como lugar de apertura originaria donde es posible prepara un nuevo encuentro del hombre con lo divino. De este modo, la esencia de lo sagrado nos abre la esencia de lo divino, que nada tiene que ver con las determinaciones y atributos del dios de la metafísica. Entonces, lo divino, en la filosofía heideggeriana, adviene frente a una continua actitud interrogadora por el sentido del ser, esto significa que lo divino es la radical alteridad que adviene en el seno del ser mismo. ${ }^{39} \mathrm{~A}$ lo divino solo se lo puede señalar, poéticamente quizás, pero no definir. Es por ello que el rechazo del dios metafísico posibilita el advenimiento de la divinidad religando, de este modo, al hombre con lo divino de un modo diferente al de la tradición occidental.

En este sentido, Picotti sostiene que la expresión último dios "no ha de ser considerada degradación ni blasfemia [respecto de dios], sino por el contrario ella destaca la singularidad de la esencia divina como una dimensión del ser, diferenciándose de su dimensión metafísica como ente supremo, solo en cuyo nivel se juegan los ateísmos y teísmos de toda especie". ${ }^{40}$ Es por ello que último dios no designa el fin de los dioses o el fin de la historia como podría interpretarse, sino que designa al otro comienzo de la historia y sus posibilidades inconmensurables. Este planteo tiene como una de sus consecuencias más relevantes reubicar lo sagrado, lo divino y lo humano junto a todos los entes en una dimensión más originaria; expresado en la consideración heideggeriana del cuarteto del mundo. Con ella, el pensador alemán, quiere señalar aquella dimensión esencial en donde se expresa "la contienda de cielo, tierra, mortales y divinos en que

37 heIdegger, Martin, Aportes a la Filosofía. Acerca del Evento, Biblos, Buenos Aires, 2003, p. 329. 38 HEIDEGGER, Martin, Nietzsche II, Destino, Barcelona, 2000, p. 396.

39 Cfr. CAPElle-dumont, Philippe, Filosofía y teología en el pensamiento de Martin Heidegger, FCE, México, 2012, p. 154.

40 PIcotTI, Dina, Heidegger: el otro comienzo del pensar y las exigencias de nuestro tiempo, Bs. As., Ed. Quádrata, 2010, p. 78. 
se $d a$ la verdad del ser en su juego ocultación-desocultación, donación y sustracción". ${ }^{41}$ Así, el hombre puede volver a habitar el mundo de un modo contemplativo, sin ejercicio de violencia; reuniendo y cuidando estas cuatro dimensiones del acontecer propio de la contingencia del mundo; donde acogiendo la apertura del cielo, salvaguardando la tierra, acompañando a los mortales y venerando lo sagrado, el hombre puede ponerse a la escucha del ser y por ende preparar un lugar de apertura sagrado para que lo divino advenga.

\section{Conclusión.}

Heidegger, con la noción de Ereignis intenta pensar al ser en cuanto tal y la diferencia con lo ente, de otro modo frente a los límites categoriales de la metafísica entendida como onto-teo-logía. El acontecimiento apropiante es el movimiento del ser y el tiempo que se dona a los entes y al hombre pero que se retrae a sí mismo. El movimiento del Ereignis es pensado por Heidegger como la donación de ser y tiempo, por eso afirma Heidegger que lo que "intentamos pensar es el Es de este Es gibt Sein, Es gibt Zeit, el Es que da ser y tiempo"42 por ello el "Ereignis ereignet"43 es decir, el acontecimiento de apropiación se expropia a la vez que se retiene o apropia a sí mismo.

El acontecimiento, entonces, es una singularidad sin modelos o esencia presupuesta, pues la originalidad de todo acontecimiento resulta ser el movimiento a partir del cual lo nuevo emerge, lo no previsto irrumpe en la realidad y escapa de los límites de la historiografía porque en todo acontecimiento hay un resto no histórico, inaprehensible, que excede los límites discursivos humanos.

En definitiva, el acontecimiento es una singularidad que adviene, que resulta imprevisto ya que excede los límites de toda lógica de pensamiento fundamentador. El acontecimiento, por ende, destruye todo horizonte onto-teo-lógico y teleológico a la vez, por lo cual impide cualquier intento de fundamentación y totalización. El acontecimiento acaece, en términos heideggerianos, como novedad, sin que puedan preverse causas; es sorpresa absoluta que no puede ser anticipada. El acontecimiento mienta, a su vez, el advenimiento y la irrupción de lo extraordinario cuyo carácter es la absoluta gratuidad. No hay un por qué en él, simplemente hay acontecimiento, se da (Es gibt) como donación de ser y tiempo; y, también, el acontecimiento constituye una constelación de sentido para el hombre. De ello se sigue la gran relevancia que la hermenéutica asume para la posición

41 Ibid., p. 79.

42 HeIDEgGeR, Martin, Tiempo y Ser, Madrid, Tecnos, 2006, p. 24.

43 HEIDEGGER, Martin, Tiempo y Ser, Madrid, Tecnos, 2006, p. 43. 
heideggeriana, en cuanto posibilita la proliferación de perspectivas interpretativas e impide toda totalización del sentido.

Entonces, el problema de la diferencia, que es el mismo problema que el de la pregunta por el ser, implica en la filosofía de Heidegger pensarlos como Ereignis; pero a su vez, pensar el Ereignis es preparar y propiciar un espacio y tiempo originarios cuya cualidad es la sacralidad. Lo sagrado es la cualidad que anuncia el despliegue, la irrupción y la posibilidad del advenimiento de lo divino, y así pues, lo divino, puede hacerse presente. Lo sagrado es la dimensión, por lo tanto, de anuncio, despliegue y acercamiento del hombre con los dioses.

Resulta, por todo ello, claro que la propuesta de Heidegger conlleva el esfuerzo por conducir al pensamiento humano hacia un lugar de contemplación y respeto hacia las dimensiones de lo real, como condición para la recuperación del sentimiento religioso que posibilite la preparación de la dimensión sagrada, que habita en todo lo que es, para esperar, de este modo, el advenimiento de lo divino.

\section{Bibliografía}

ARISTÓTELES (1998), Metafísica, traducción de T. Calvo Martínez, Madrid: Gredos.

CORTI, E. (1985), "La inteligencia y lo inteligible”, en Pensamiento y Realidad, Bs. As: Usal. CAPELLE-DUMONT, P., Filosofía y teología en el pensamiento de Martin Heidegger, FCE, México, 2012.

CAPUTO, J. D., The mistical elements in Heidegger 's thought, Ohio University Press, 1978. CRAGNOLINI, M. (2007) Derrida, un pensador del resto. Buenos Aires: La Cebra.

EGGERS LAN, C., y JULIÁ, V. E., (1994) Los filósofos presocráticos, Madrid: Gredos.

ESPERÓN, J. P., "Metafísica y post-filosofía en el pensamiento de Martin Heidegger", en Rihumso. Revista de Investigación en Humanidades y Ciencias Sociales. Dpto de Humanidades y Ciencias Sociales de la Universidad Nacional de La Matanza, San Justo, Bs. As. Año II, no 4, 2013.

ESPERÓN, J. P., "Metafísica y religión. Caminos hacia un replanteamiento de la cuestión de lo divino a partir de las filosofías de Heidegger y Nietzsche", en Horizontes filosóficos. Revista de Filosofía, Humanidades y Ciencias Sociales, ed. por las áreas "Epistemología" y "Problemáticas especiales de la filosofía: el lenguaje", Dpto de Filosofía, Facultad de Humanidades, Universidad Nacional del Comahue, Neuquén, Argentina. Año 2, no2, 2012. 
FINK, E. (2000), La filosofía de Nietzsche. Madrid: Alianza.

HEIDEGGER, M., (1971), Ser y tiempo, trad, J. Gaos, México: FCE.

HEIDEGGER, M., (2000), "La esencia del fundamento" en Hitos, Traducción de H. Cortés y A. Leyte, Madrid: Alianza.

HeIDegger, M., (1990), Identidad y Diferencia, Traducción de H. Cortés y A. Leyte, Barcelona: Anthropos.

HeIDegGer, M., (1969), Introducción a la Metafísica, Traducción de E. Estiú, Bs. As: Nova. HeIDEgGer, M., (2003), Aportes a la filosofía. Acerca del evento, traducción de Dina Picotti, Buenos Aires: Almagesto.

HEIDEGGER, M., (2000), Nietzsche, traducción de Juan Luis Vernal, Madrid: Destino.

HEIDEGGER, M., (1990), Conceptos fundamentales, Madrid: Alianza.

HEIDEgGeR, M., (2000), “Carta sobre el Humanismo” en Hitos, Madrid: Alianza.

HEIDEGGER, M., (2000), “Introducción a ¿Qué es metafísica?”, publicado en Hitos, Madrid: Alianza.

HEIDEgGeR, M., (1998), "La sentencia de Anaximandro", publicada en Caminos de bosque, Madrid: Alianza.

HeIDEgGeR, M., (2000), “De la esencia de la verdad”, en Hitos, Madrid: Alianza.

HEIDEGGER, M., Tiempo y Ser, Madrid, Tecnos, 2006.

PLATón (1986), República. Madrid: Gredos.

PICOTTI, D. (2010), Heidegger: el otro comienzo del pensar y las exigencias de nuestro tiempo, Bs. As., Ed. Quádrata.

PÖGgeler, O. (1986), El camino del pensar de Martin Heidegger, Alianza, Madrid.

SANTIESTEBAN, L. C. (2009), "Heidegger y Vattimo: intérpretes de Nietzsche", en Diánoia, vol. LIV, no 63, revista de la UNAM, México.

vattimo, G. (1986) Las aventuras de la diferencia. Barcelona: Península. 